\title{
(6) OPEN ACCESS \\ Double-lumen arterial balloon catheter technique for Onyx embolization of dural arteriovenous fistulas: initial experience
}

\author{
Albert Ho Yuen Chiu, ${ }^{1,2}$ Grace Aw, ${ }^{1}$ Jason David Wenderoth ${ }^{1}$
}

\begin{abstract}
${ }^{1}$ Department of Medical Imaging, The Prince of Wales Hospital, Randwick, New South Wales, Australia ${ }^{2}$ Neurological Intervention and Imaging Service of Western Australia, Sir Charles Gairdner Hospital, Nedlands, Western Australia, Australia
\end{abstract}

\section{Correspondence to} Dr Albert Ho Yuen Chiu, Neurological Intervention and Imaging Service of Western Australia, Sir Charles Gairdner Hospital, 1st Floor, G Block, Hospital Ave, Nedlands, WA 6009, Australia; albert.h.chiu@gmail.com

Received 6 April 2013 Accepted 22 May 2013 Published Online First 8 June 2013

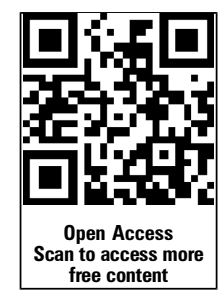

\begin{tabular}{l}
\hline To cite: Chiu AHY, Aw G, \\
Wenderoth JD. \\
J Neurolntervent Surg \\
2014;6:400-403. \\
\hline
\end{tabular}

\begin{abstract}
Background Dural arteriovenous fistulas are vascular malformations with variable clinical symptoms that range in severity from completely asymptomatic to seizures, dementia, loss of vision and intracranial hemorrhage. Historically, surgical obliteration was the treatment of choice but, more recently, endovascular embolization has become the first-line treatment. The liquid embolic agent Onyx (ethyl vinyl copolymer) has become the agent of choice, but problems with reflux around the delivery microcatheter and inadvertent venous penetration have arisen.

Methods and results We present six cases in which the double-lumen balloon microcatheter was used to transarterially embolize dural arteriovenous fistulas via injection of Onyx through the wire lumen. Depending on the individual pathology a venous balloon was also used in some cases. The advantages and disadvantages of the use of these devices are discussed.

Conclusions We consider that the use of the doublelumen balloon technique for fistula embolization has the potential for reducing overall procedural times, procedural failures and catheter retention in certain situations. In such cases we would advocate this as a first-line technique. When lower profile, more navigable balloon catheters become available, this may become the standard of care.
\end{abstract}

\section{INTRODUCTION}

Dural arteriovenous fistulas (dAVFs) are vascular malformations which may present with a range of symptoms and signs including intracranial hemorrhage. Surgical obliteration was historically the treatment of choice, but embolization has recently become the first-line treatment. ${ }^{1}$ Successful and durable transarterial closure of dAVF requires penetration from the arterial side of the fistula into the venous side so, prior to the advent of Onyx, embolization was frequently achieved by transvenously occluding-where safe and feasible-the dural venous sinus receiving the fistula outflow, leading to upstream thrombosis of the arterial and venous components of the fistula.

Onyx (ev3 Neurovascular, Irvine, California, USA) has become the preferred embolysate due to its cohesive and non-adhesive nature which assists in controlled penetration of the fistula. ${ }^{2}$ Two significant drawbacks with Onyx are arterial reflux alongside the delivery microcatheter and inadvertent venous penetration beyond the venous side of the fistula itself into an otherwise useful or potentially useful normal venous sinus lumen.

We present six cases in which a new doublelumen distal arterial balloon occlusion technique was used and discuss the advantages and disadvantages of this technique.

\section{TECHNIQUE}

In each case the procedure was performed under general anesthesia. Right common femoral artery access was obtained and a 6 Fr Envoy MPD guide catheter (Cordis Corporation, Bridgewater, New Jersey, USA) was advanced into the relevant external carotid artery over a Terumo 0.035 inch angled glide wire (Terumo Corporation, Tokyo, Japan). A $4 \times 10 \mathrm{~mm}$ Scepter C balloon (Microvention, Tustin, California, USA) was then advanced through the guide catheter using a Transend EX Platinum 0.014 inch microwire (Boston Scientific, Natick, Massachusetts, USA) into the target artery (figure 1).

For cases where a venous balloon was employed, a 6 Fr Envoy catheter was advanced over a glide wire to the relevant jugular bulb via a right common femoral vein access. A Copernic $8 \times 80 \mathrm{~mm}$ balloon (Balt Extrusion, Montmorency, France) was then advanced coaxially over a Transend microwire into the relevant dural sinus (figure 2).

Both arterial and venous balloons were inflated under fluoroscopy prior to dimethyl sulfoxide and Onyx injection, and inflation of the venous balloon was maintained for 3-5 min intervals for the duration of embolysate injection. The arterial balloon was left inflated for the duration of the Onyx injections. Inflation of the arterial balloon was undertaken with caution due to its relative oversizing in relation to the parent vessel, much in the same manner as underinflation of semicompliant but oversized balloons is routinely employed in balloon angioplasty for vasospasm in the pial circulation. Both balloons were deflated for angiography through the arterial guide catheter to confirm fistula occlusion.

Variations or procedural events are described below.

\section{CASE PRESENTATIONS}

The details of each case are listed in table 1.

\section{Case 1}

A 56-year-old man with hypertension, dyslipidemia and obesity presented with right hemiplegia, receptive dysphasia and confusion. Investigations 


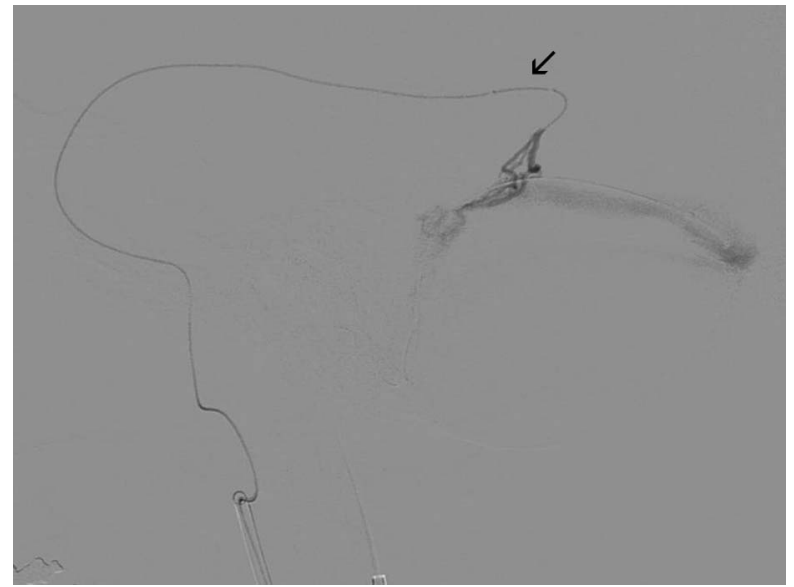

Figure 1 Lateral projection angiogram via the arterial balloon catheter within the right middle meningeal artery demonstrating the fistula.

demonstrated a left parietotemporal hemorrhage and a Cognard IV dAVF. Embolization was completed from the left middle meningeal artery (MMA) with no complications. After the procedure the patient recovered from his hemiplegia and confusion but dysphasia persisted and he was therefore discharged to a rehabilitation unit.

\section{Case 2}

A 62-year-old man with hypertension and hypercholesterolemia was admitted for embolization of an incidentally discovered dAVF in 2006 but the patient was lost to follow-up. He was reinvestigated upon development of headaches after cardiac surgery 3 months previously which revealed a Cognard III fistula. During the procedure an attempt was made to wedge a Marathon microcatheter (ev3 Neurovascular) within the smaller accessory meningeal artery, but intractable arterial reflux occurred and hence the larger MMA was catheterized using the balloon catheter. Embolization was completed uneventfully and the patient was discharged the following day.

\section{Case 3}

A 62-year-old woman presented with pulsatile tinnitus and was found to have a Cognard IIa+b dAVF. Onyx was injected from

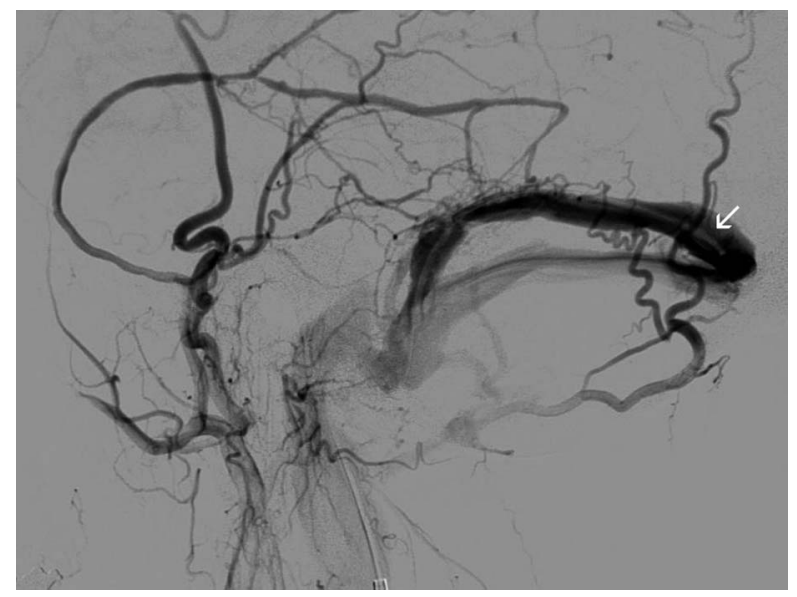

Figure 2 Lateral projection angiogram via the arterial guide catheter demonstrating the filling defect of the venous balloon catheter within the right transverse sinus.
Table 1 Details of the six cases treated

\begin{tabular}{|c|c|c|c|}
\hline Case & Arterial supply & Venous drainage & $\begin{array}{l}\text { Balloons } \\
\text { used }\end{array}$ \\
\hline 1 & $\begin{array}{l}\text { Left occipital artery and } \\
\text { MMA, minor pial supply from } \\
\text { left posterior inferior } \\
\text { cerebellar artery }\end{array}$ & $\begin{array}{l}\text { Left vein of Labbe and } \\
\text { cortical veins }-> \\
\text { cavernous sinus and SSS } \\
\text { Varices over the Sylvian } \\
\text { fissure and parietal lobe }\end{array}$ & Arterial \\
\hline 2 & $\begin{array}{l}\text { MMA and accessory } \\
\text { meningeal branches of the } \\
\text { left external carotid artery }\end{array}$ & $\begin{array}{l}\text { Cortical veins }-> \\
\text { Labbe }-> \\
\text { Left transverse sinus }\end{array}$ & Arterial \\
\hline 3 & $\begin{array}{l}\text { Bilateral external carotid, } \\
\text { mainly right MMA }\end{array}$ & Right transverse sinus & $\begin{array}{l}\text { Arterial and } \\
\text { venous }\end{array}$ \\
\hline 4 & Left MMA & $\begin{array}{l}\text { Cortical veins and large } \\
\text { varix -> } \\
\text { SSS }\end{array}$ & $\begin{array}{l}\text { Arterial and } \\
\text { venous }\end{array}$ \\
\hline 5 & Bilateral MMA & $\begin{array}{l}\text { Posterior SSS, left } \\
\text { transverse sinus }\end{array}$ & $\begin{array}{l}\text { Arterial and } \\
\text { venous }\end{array}$ \\
\hline 6 & Right MMA anterior division & SSS & $\begin{array}{l}\text { Arterial and } \\
\text { venous }\end{array}$ \\
\hline
\end{tabular}

the right MMA with the venous balloon in the right transverse/ sigmoid sinus and a diagnostic catheter was inserted in the left common carotid artery for angiography. The rationale for using venous protection in this case was the presence of an otherwise normal transverse sinus which did not require sacrifice per se, and the questionable presence of an antegradely draining vein of Labbé into the milieu of the fistulous network. During one of the arterial balloon re-inflations the balloon inflated beyond the margins of the MMA consistent with vessel rupture (figure 3). The embolization was completed with both balloons inflated and Onyx was injected via the balloon catheter as it was deflated and withdrawn. Successive angiography via the guide catheter as this was performed demonstrated immediate cessation of extravasation from the MMA. On-table flat panel CT was performed after withdrawal of the arterial balloon catheter, showing no evidence of an extradural hematoma. After the procedure the patient was asymptomatic and she was discharged the following day.

\section{Case 4}

A 47-year-old male ex-smoker presented with acute onset of leftsided weakness and numbness and a history of two similar but

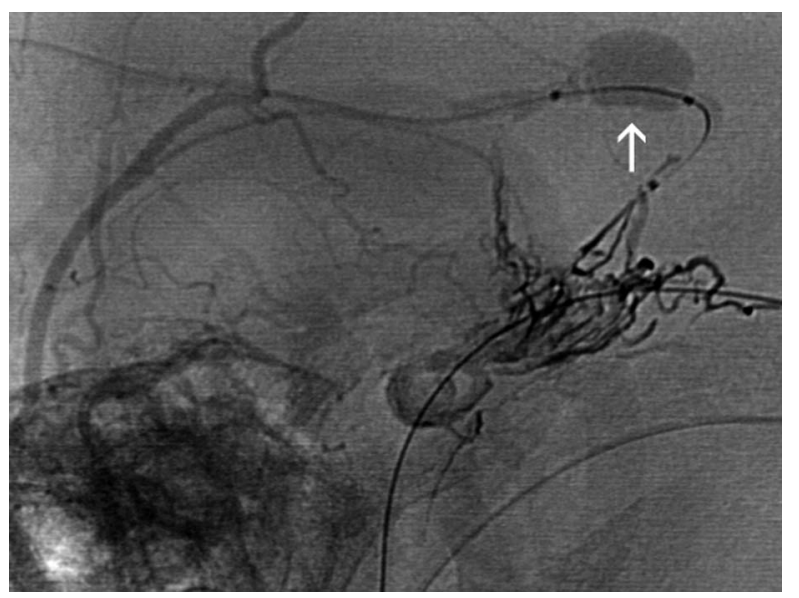

Figure 3 Non-subtracted lateral projection angiogram demonstrating the size and shape of the arterial balloon suggestive of rupture. 
self-limiting episodes. Investigations demonstrated a Cognard IV dAVF with no hemorrhage. In this case it was considered desirable to preserve the superior sagittal sinus (SSS) if possible in order to restore a more functionally normal pattern of cerebral venous drainage. A strategy deploying a venous side balloon was therefore employed. Successful embolization was performed from the left MMA with the venous balloon in the SSS. The SSS was preserved and reverted to normal cortical drainage at the end of the procedure. The patient made a gradual recovery and was discharged home 5 days after the procedure.

\section{Case 5}

A 69-year-old man presented with a sudden onset severe headache and right homonymous hemianopia. Investigations revealed a left occipital hemorrhage and Cognard IV dAVF (figure 4). A venous balloon was placed in the SSS and successful embolization was completed sequentially from the right MMA and then the left MMA during the same procedure (figure 5). The SSS was preserved (figure 6) and the patient was discharged the following day.

\section{Case 6}

A 61-year-old man with hypertension presented with left hemiparesis and was found to have a Cognard III dAVF on angiography. This was successfully embolized from the anterior division of the right MMA with a venous balloon in the SSS. The procedure was uncomplicated and the patient was discharged home 2 days after the procedure.

\section{DISCUSSION}

We have described six cases where a double-lumen balloon microcatheter has been used for dAVF embolization. To our knowledge this is the first case series of such an application, although use of proximal arterial balloon occlusion has been described previously. ${ }^{3-5}$

There are numerous advantages of this technique. First, the balloon is able to simulate a 'wedge and plug' effect ${ }^{4}$ in larger vessels, which is especially useful in lesions with tortuous arterial feeders where difficulty in reaching a distal point for embolization is expected or experienced, or where multiple feeding arteries arise from a common trunk. A 'path of least resistance'

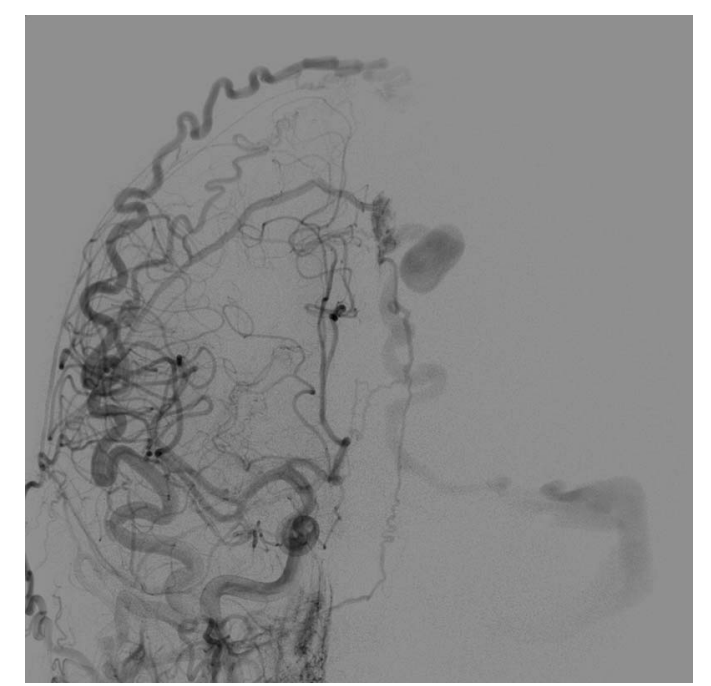

Figure 4 Townes projection angiogram from the right common carotid artery demonstrating the dural fistula with the venous varix which drained into the sagittal sinus and left transverse sinus.

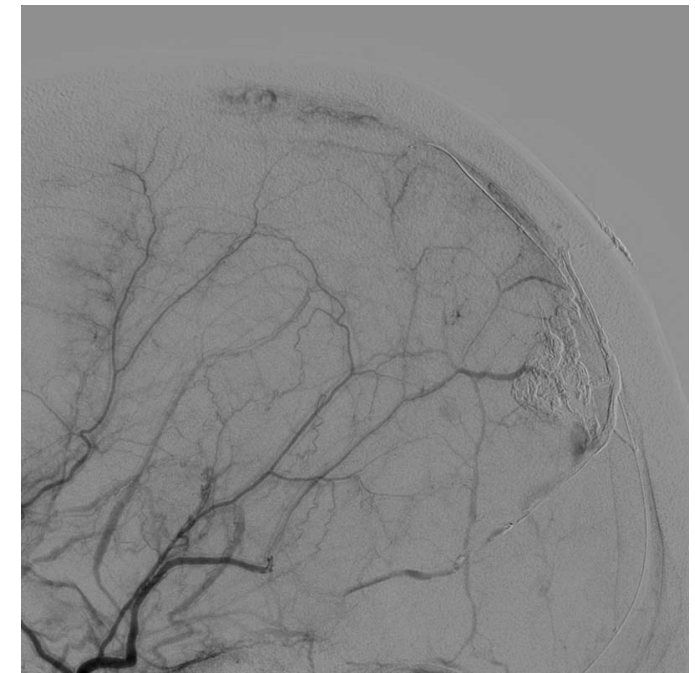

Figure 5 Lateral projection angiogram with right external carotid injection demonstrating the deflated venous balloon within the superior sagittal sinus, Onyx cast and slow flow from a posterior branch of the middle meningeal artery due to downstream occlusion.

is produced towards the dAVF, promoting antegrade embolysate flow. Although use of a larger non-balloon microcatheter will cause 'wedging' in a more proximal vessel, this in itself is no guarantee of forming an antegradely decreasing pressure gradient or against embolysate reflux, hence an Onyx plug will still probably be required, similar to cases where smaller flowdirected microcatheters are wedged more distally.

On average, in our experience, formation of a satisfactory preliminary Onyx 'plug' requires between 5 and $25 \mathrm{~min}$ of cyclic injections. By negating the need to spend time creating the initial Onyx plug, retrograde arterial reflux of Onyx and hence risk of catheter retention, overall fluoroscopy time and Onyx volume can be reduced, as was experienced in our cases. Immediate antegrade flow of Onyx towards the fistula occurred in all patients in our case series and no reflux around the inflated balloon was identified. The balloon also reduces flow

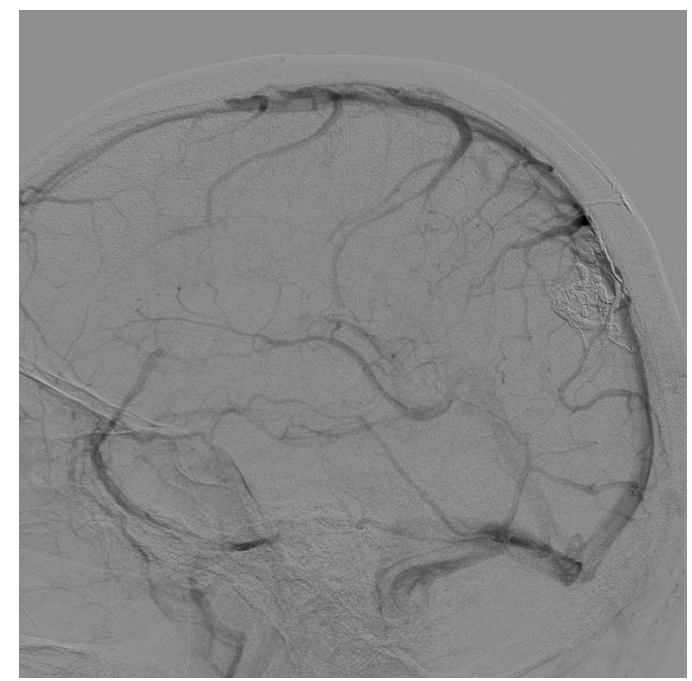

Figure 6 Lateral projection angiogram at completion of the procedure from the left internal carotid artery demonstrating preservation of the transverse sinus providing a drainage pathway for normal brain parenchyma. 
through the fistula, ${ }^{3}{ }^{4}$ lowering the risk of unwanted or excessive venous penetration. Complete embolization was achieved in all cases.

Second, large vein penetration can further be diminished where desired by employing a venous side balloon as described in cases 3-6. Furthermore, segments of venous sinus draining solely the fistula, which would historically have been sacrificed with coils, can be restored to normally functioning vessels used for cerebral drainage, reducing the likelihood of ongoing intracranial venous hypertension due to persistent inadequate cerebral venous drainage. While the authors are cognisant of the fundamental principle of achieving dAVF cure by achieving artery-to-vein penetration, complete closure of large segments of major dural sinuses is frequently unnecessary and, in some cases, undesirable. Use of a venous protection balloon can convert many of these treatments into curative-reconstructive rather than curative-deconstructive procedures.

Third, similar to using separate balloon and embolization microcatheters, the balloon can be used to prevent reflux into adjacent branches ${ }^{45}$ but, with a double-lumen device, the artery only needs to be catheterized once, reducing the risk of trauma and vasospasm rendering re-access with the second catheter difficult.

Similar to the embolization catheter/balloon catheter technique and in keeping with use of semicompliant balloons in angioplasty for vasospasm, balloon inflation must be undertaken with care to avoid vessel perforation, as occurred in case 3 . The torquability and robustness of the larger microwires usable in the double-lumen balloon can also be advantageous. In our practice we currently use Onyx exclusively for dAVF embolization as it allows for a slower, more controlled injection. ${ }^{6}$ Onyx has been suggested as a more durable agent than nbutylcyanoacrylate in dAVF embolization ${ }^{2}$ but, regardless of the agent, it is likely that use of a balloon allows for a more controlled injection of any liquid embolic agent.

A number of trade-offs are identified. Use of a balloon microcatheter adds complexity to the preparation for the procedure as the balloon microcatheter needs to be prepared. The embolysate volume required may be higher because of the larger dead space of the balloon catheter $(0.44 \mathrm{~mL})$ and artery proximal to the fistula. This is more than likely offset in most cases by the minimization of reflux and excessive penetration into large/ normal veins which could ideally be preserved. The stiffer catheter was, in our experience, slightly more difficult to navigate than traditional catheters compatible with dimethyl sulfoxide and may render access difficult in tortuous arteries but, in our series, this was felt to be an acceptable trade-off. In our cases, this trade-off did not prevent us from delivering the catheter to a satisfactorily distal position. The operator must also be cognisant of the risk of potential vessel rupture which has also been described in a mixed case series in a patient undergoing intracranial arteriovenous malformation leading to neurological morbidity and requirement for surgical hematoma evacuation. ${ }^{7}$

\section{CONCLUSION}

We have described a number of cases in which a double-lumen balloon microcatheter was used for Onyx embolization of dAVFs. We believe this technique has the potential for streamlining the procedure in certain situations such as inaccessibility of the distal arterial feeder close to the point of fistula, multiple feeders from a common trunk and short segment of reflux tolerance with potentially lower overall procedural times, procedural failures and catheter retention. In such cases we would advocate this as a first-line technique. When lower profile, more navigable balloon catheters become available, this may become the standard of care.

Acknowledgements We would like to thank Culpan Medical Australia for their assistance in funding the Open Access fee for this manuscript.

Contributors AHYC, GA and/or JDW performed the procedures described in this study. AHYC and JDW conceived the paper. AHYC drafted the article. All three authors revised it for content and gave final approval for the version to be published.

Funding Funding for Open Access was discussed and secured from Culpan Medical Australia.

Disclaimer The views expressed in the article are of the authors only, and not Culpan Medical Australia nor Microvention Terumo.

Competing interests AHYC was sponsored by Culpan Medical Australia, the Australian and New Zealand distributor of Microvention Terumo products, for travel/ accommodation/meeting expenses to a Microvention Terumo sponsored Fellow's Conference. No monies were given directly and this study was not discussed at the meeting. None of the authors have relevant competing interests. No financial or material assistance was received in relation to the preparation of this manuscript.

\section{Patient consent Obtained.}

Provenance and peer review Not commissioned; externally peer reviewed.

Open Access This is an Open Access article distributed in accordance with the Creative Commons Attribution Non Commercial (CC BY-NC 3.0) license, which permits others to distribute, remix, adapt, build upon this work non-commercially, and license their derivative works on different terms, provided the original work is properly cited and the use is non-commercial. See: http://creativecommons.org/ licenses/by-nc/3.0/

\section{REFERENCES}

1 Hu YC, Newman CB, Dashti SR, et al. Cranial dural arteriovenous fistula: transarteria Onyx embolization experience and technical nuances. J Neurointervent Surg 2011;3:5-13.

2 Rabinov JD, Yoo AJ, Ogilvy CS, et al. ONYX versus n-BCA for embolization of cranial dural arteriovenous fistulas. J Neurointervent Surg 2013;5:306-10.

3 Andreou A, loannidis I, Nickolaos N. Transarterial balloon-assisted glue embolization of high-flow arteriovenous fistulas. Neuroradiology 2008;50:267-72.

4 Shi ZS, Loh Y, Duckwiler GR, et al. Balloon-assisted transarterial embolization of intracranial dural arteriovenous fistulas. J Neurosurg 2009;110:921-8.

5 Spiotta AM, Hughes G, Masaryk TJ, et al. Balloon-augmented Onyx embolization of a dural arteriovenous fistula arising from the neuromeningeal trunk of the ascending pharyngeal artery: technical report. J Neurointervent Surg 2011;3:300-3.

6 Nogueira RG, Dabus G, Rabinov JD, et al. Preliminary experience with Onyx embolization for the treatment of intracranial dural arteriovenous fistulas. AJNR Am J Neuroradiol 2008;29:91-7.

7 Jagadeesan $B D$, Grigoryan $M$, Hassan $A E$, et al. Endovascular balloon-assisted embolization of intracranial and cervical arteriovenous malformations using dual lumen co-axial balloon microcatheters and Onyx: initial experience. Neurosurgery. Published Online First 25 February 2013. doi: 10.1227/NEU.0b013e31828d602b 